\title{
BMJ Open Hypertension knowledge and treatment initiation, adherence, and discontinuation among adults in Chennai, India: a cross-sectional study
}

\author{
Nikkil Sudharsanan (D) ,1,2 Mohammed K Ali, ${ }^{3,4}$ Margaret McConnell ${ }^{5}$
}

To cite: Sudharsanan N, Ali MK, McConnell M. Hypertension knowledge and treatment initiation, adherence, and discontinuation among adults in Chennai, India: a crosssectional study. BMJ Open 2021;11:e040252. doi:10.1136/ bmjopen-2020-040252

- Prepublication history for this paper is available online. To view these files, please visit the journal online (http://dx.doi. org/10.1136/bmjopen-2020040252).

Received 11 May 2020 Revised 15 0ctober 2020 Accepted 22 December 2020

Check for updates

(c) Author(s) (or their employer(s)) 2021. Re-use permitted under CC BY-NC. No commercial re-use. See rights and permissions. Published by BMJ.

${ }^{1}$ Heidelberg Institute of Global Health, Heidelberg University, Heidelberg, Germany

${ }^{2}$ LEAD at Krea University,

Chennai, India

${ }^{3}$ Department of Family and Preventive Medicine, Emory University, Atlanta, GA, USA ${ }^{4}$ Hubert Department of Global Health, Rollins School of Public Health, Emory University, Atlanta, GA, USA

${ }^{5}$ Department of Global Health and Population, Harvard T.H.

Chan School of Public Health, Boston, MA, USA

Correspondence to Dr Nikkil Sudharsanan; nikkil.sudharsanan@uniheidelberg.de

\section{ABSTRACT}

Introduction A substantial share of urban Indians with diagnosed hypertension do not take regular treatment, potentially due to poor knowledge of hypertension consequences and treatment options. We describe hypertension knowledge and beliefs, treatment patterns, and reported reasons for treatment non-use among adults with diagnosed hypertension in Chennai, India.

Methods We collected data on 833 adults ages 30+ with physician diagnosed hypertension using a door-todoor household survey within randomly selected wards of Chennai. We described the proportion of individuals who were not taking daily medications and their reported reasons for not doing so. Next, we described individuals' knowledge of hypertension consequences and how to control blood pressure (BP) and assessed the association between knowledge and daily treatment use.

Results Over one quarter (28\% (95\% Cl $25 \%$ to $31 \%)$ ) of diagnosed individuals reported not taking daily treatment. The largest proportion (18\% (95\% Cl $16 \%$ to $21 \%)$ ) were individuals who had discontinued prior treatment use. The primary reason individuals reported for non-daily use was that their BP had returned to normal. Just $23 \%$ (95\% Cl $20 \%$ to $26 \%$ ) of individuals listed BP medications as the most effective way to reduce BP; however, these individuals were $11 \%$ points (95\% Cl $4 \%$ to $19 \%$ ) more likely to take daily medications. Conversely, $43 \%$ (95\% Cl $40 \%$ to $47 \%$ ) of individuals believed that BP medications should be stopped from time to time and these individuals were $15 \%$ points $(95 \% \mathrm{Cl}-0.21$ to -0.09 ) less likely to take daily treatment. While awareness of the consequences of hypertension was poor, we found no evidence that it was associated with taking daily medications.

Conclusions There were large gaps in consistency of BP medication use which were strongly associated with knowledge about BP medications. Further research is needed to identify whether addressing beliefs can improve daily treatment use among individuals with diagnosed hypertension.

\section{INTRODUCTION}

Hypertension is the leading modifiable risk factor for mortality worldwide. ${ }^{1}$ Controlling blood pressure (BP) through daily, lowcost, medications substantially reduces the
Strengths and limitations of this study

- We provide some of the first evidence on hypertension knowledge and beliefs, especially regarding blood pressure medications, among adults with diagnosed hypertension in a major Indian city.

- We also link individuals' hypertension knowledge to reported treatment behaviour to determine if more knowledgeable individuals are more likely to take daily hypertension treatment.

- The primary limitation of our study is that it is based on a non-probability sample of individuals from a single city in India and may not be generalisable to all urban Indians with hypertension.

- Our study was not designed to estimate the causal effect of individuals' knowledge and beliefs on blood pressure outcomes and is best interpreted as hypothesis generating.

negative consequences of hypertension and is one of the most cost-effective ways of reducing mortality. ${ }^{2-4} \mathrm{BP}$ control is especially pressing in urban India, since over $30 \%$ of adults over the age of 30 are hypertensive and this prevalence is expected to increase substantially as the population ages. ${ }^{5-7}$ Indeed, recent observational studies have found that improving $\mathrm{BP}$ control has the potential to result in large population-wide improvements in mortality in urban India and similar contexts. ${ }^{89}$

Despite the widespread availability of antihypertensive medications, ${ }^{10}$ several recent studies have found that BP treatment use among individuals diagnosed with hypertension in India is low. ${ }^{71} 12$ For example, among adults in New Delhi and Chennai with diagnosed hypertension, only an estimated $18 \%-37 \%$ reported taking medications. ${ }^{7}$ Similarly, a recent national study found that just $31 \%$ of hypertensive adults living in urban areas reported taking hypertension treatment. ${ }^{11}$ These studies reveal substantial treatment gaps among urban Indians with 
diagnosed hypertension yet the potential reasons behind this pattern remain unclear.

Knowledge of the importance and most effective ways of controlling BP is critical for initiating and adhering to hypertension treatment. ${ }^{13-16}$ Individuals may not initiate or adhere to treatment if they are not fully aware of the negative consequences of uncontrolled hypertension. Alternatively, individuals may understand the importance of BP control, but not know that taking medications daily is the most effective way of controlling BP. Limited qualitative evidence from India suggests that individuals with hypertension are not aware of the link between hypertension and stroke and heart disease, and while individuals are generally aware of the importance of healthy lifestyle habits, they do not necessarily understand the specific and most effective ways of controlling BP. ${ }^{17} 18$ These largely qualitative studies have focused more on knowledge of preventative measures than knowledge of BP medications and did not link knowledge to medication adherence.

We investigate the potential reasons behind low hypertension treatment among adults diagnosed with hypertension in Chennai-India's sixth most populous city. We begin by estimating the share of individuals that do not take daily treatment. We then divide our sample between those who never initiated treatment, those who take treatment but irregularly, and those who took treatment in the past but have since discontinued it. Among these individuals, we report the most commonly stated reasons for not taking daily treatment. Next, we describe individuals' knowledge of hypertension consequences and treatment and assess whether individuals who are more knowledgeable are also more likely to take daily treatment. Findings from this work will inform the development of effective interventions by exploring modifiable pathways that may be responsible for poor BP management in urban India and similar contexts.

\section{DATA AND METHODS}

\section{Setting}

Our study was conducted in Chennai, the capital city of the southern state of Tamil Nadu. Tamil Nadu has the sixth highest life expectancy among all Indian states (72.1) and was ranked as having the ninth highest health index-a composite measure made up of 23 health and health service indicators-by the government of India. ${ }^{192}$ Chennai is the most populous city within the state and the sixth most populous city in India (2011 population of 4.7 million individuals). ${ }^{21}$ Chennai has a relatively old age distribution within India: $53 \%$ is older than age $30 \%$ and $20 \%$ older than 50 . Hinduism is the most common religion in Chennai $(82 \%)$, followed by Islam $(9 \%)$ and Christianity $(8 \%) .{ }^{22}$

\section{Target population and sampling}

We recruited individuals aged 30 and older in Chennai who self-reported physician-diagnosed hypertension between June and August of 2019. Surveys were collected by a Chennai-based research organisation that locally recruited survey teams and conducted all interviews in Tamil, the local language. We used a geographically stratified quota sampling approach to identify respondents. ${ }^{23}$ We started with randomly selecting 50 of Chennai's 200 wards with weights proportional to share of the Chennai population living in the ward as of the 2011 census. Within selected wards, enumerators selected a random starting street; if the starting street was primarily commercial, enumerators moved to parallel streets until they reached a street with residential homes. Enumerators then used a door-to-door two-step procedure to identify eligible individuals. Enumerators first asked a household respondent if anyone aged 30 and above in the household had physician-diagnosed hypertension, and only if confirmed, conducted the main interview. We attempted to enroll an approximately equal number of men and women and older and younger adults within each ward. Enumerators interviewed only one respondent per household-selected by the enumerator to best balance the age and sex distribution of respondents within the ward-if multiple individuals reported having hypertension. If no one in the household reported having hypertension, enumerators moved on to the next household. Enumerators repeated this procedure until they reached their target sample of 15-20 individuals per ward. Households were only visited once and not recontacted. Of approximately 1243 individuals approached, 833 (67\%: 420 men, 413 women) agreed to participate. Survey teams collected surveys at multiple times during the day and on weekends to ensure that the sample contained both working and non-working individuals.

\section{Measurements}

Survey teams administered a questionnaire collected digitally on handheld tablets to reduce surveying errors. Enumerators asked participants about sociodemographic characteristics, BP treatment information, and their knowledge of the consequences of hypertension, how to control hypertension, and their beliefs regarding how regularly hypertension treatment should be taken. We had complete data on all relevant variables for all 833 respondents.

\section{Main outcomes}

Our outcome of interest was whether an individual reported taking daily medications to control their BP. To measure this, we first asked individuals, 'did you ever take medication to control your blood pressure?' Individuals were then asked if they were currently taking medication to control their BP, if so, how often they took them. Based on these questions, we classified individuals as taking daily medications if they reported that they were currently taking medication and that they took it daily. We additionally classified individuals who did not report daily treatment use into three categories, those who: never took BP medications, currently took medications but irregularly (individuals who reported currently taking 
medications less than daily), and took medication previously but discontinued it.

\section{Explanatory variables}

Among those not taking daily medications, we asked why they do not take treatment daily, why they stopped taking treatment, or why they never took treatment depending on which of the three categories of non-daily medication use they were in. This was asked as an open-ended question that was translated and categorised at the conclusion of the study.

For knowledge of BP, we asked individuals "what are the consequences of having long-term uncontrolled blood pressure?' Individuals were not shown possible answers and were allowed to provide as many responses as they wanted. At the conclusion of the study, we classified the responses into the following categories: stroke, heart problems, kidney problems, eye problems, faintness, headaches, tiredness, limb pains and weakness, and other $(9 \%$ of respondents provided a response classified as other). Next, we measured individuals' knowledge on how to reduce BP. To do this, we presented individuals with cards, each containing a potential way of reducing BP drawn from the clinical literature. ${ }^{24}$ Options included taking medications, reducing weight, reducing smoking, reducing alcohol consumption, reducing salt consumption, dietary changes other than salt reduction, increasing exercise and reducing stress and tension. Each option was written on the card in both English and Tamil. Next, we asked individuals which three options they believed were most effective for controlling BP, and among these three, which was the most effective. While there is limited clinical evidence on the impact of reducing stress on BP, we included this option since it was frequently mentioned by individuals during our study piloting, where we conducted qualitative interviews with a small number of respondents and asked them to simply list all the ways they knew of controlling hypertension. Lastly, we measured individuals' knowledge that BP medications should be taken continuously by asking individuals if they agreed with the statement 'Do you think you should stop taking your BP medications from time to time?'

Based on these questions we classified individuals as having accurate knowledge of hypertension consequences if they indicated that stroke and heart problems are important consequences of uncontrolled hypertension and accurate knowledge of the most effective ways of controlling hypertension if they indicated that taking BP medications is one of the three most effective ways of controlling BP. Lastly, we classified individuals as having accurate knowledge of the need for continuous treatment if they disagreed with the statement that BP medication should be stopped from time to time.

\section{Statistical methods}

We reported the proportion of individuals in each category of non-daily treatment. We then presented the proportions who report each reason for non-daily use (separately for each category of non-daily treatment) and the proportions who report accurate knowledge of hypertension consequences, the most effective way of controlling hypertension and the need for continuous treatment. Next, we investigated the association between knowledge and daily medication use as the difference in the proportion of individuals who reported daily BP treatment use across each of the knowledge exposures (separately for each exposure). We carried out all analyses with $\mathrm{R}$ software and made all figures using the ggplot2 package.

\section{Participant consent}

All respondents were informed about the benefits and risks of participating in the study and gave written consent before being interviewed.

\section{Patient and public involvement}

Patients or the public were not involved in the design, or conduct, or reporting, or dissemination plans of our research.

\section{Data sharing statement}

Data are available by emailing nikkil.sudharsanan@uniheidelberg.de and will be made available online after publication.

\section{RESULTS}

\section{Descriptive characteristics}

In this sample, $67 \%$ of women and $72 \%$ of men were aged 50 years or older (table 1 ). The majority of respondents were married, with a greater share of current marriage among men (94\% for men compared with $68 \%$ for women) due to higher levels of widowhood among women (31\% for women compared with $3 \%$ for men). Hinduism was the most common religion ( $81 \%$ of women and $82 \%$ of men), followed by Christianity (11\% of women and $10 \%$ of men) and Islam (8\% of women and $7 \%$ of men). Women were more likely to report less than primary schooling (35\% of women compared with $18 \%$ of men). For occupation, $53 \%$ of women reported housework, followed by skilled work $(27 \%)$. For men, skilled work was the most common occupation $(59 \%)$, followed by not working $(30 \%)$.

\section{Hypertension treatment patterns and self-reported reasons for non-daily treatment}

Over one quarter (28\% (95\% CI $25 \%$ to $31 \%$ )) of diagnosed individuals reported not taking daily treatment (figure 1). Among those that reported not taking daily medications, the largest proportion were individuals who had discontinued medication that they were taking previously (64\% (95\% CI 58\% to $70 \%$ ) of those who reported not taking daily treatment or $18 \%$ (95\% CI $16 \%$ to $21 \%$ ) of the entire sample). The remaining $36 \%$ of individuals who reported not taking daily treatment were split equally between those who reported never initiating treatment and those who reported taking treatment but irregularly. 
Table 1 Descriptive characteristics of the sample by sex, 833 adults ages 30 and above with physician confirmed hypertension, Chennai, India, 2019

\begin{tabular}{lll}
\hline & \multicolumn{2}{l}{ Percentage of respondents } \\
\cline { 2 - 3 } & Female (n=420) & Male (n=413) \\
\hline Age groups & & 0.28 \\
\hline $30-50$ & 0.33 & 0.58 \\
\hline $50-70$ & 0.58 & 0.14 \\
\hline $70+$ & 0.09 & \\
\hline Marital status & & 0.94 \\
\hline Currently married & 0.68 & 0.03 \\
\hline Widowed & 0.31 & 0.02 \\
\hline Never married/divorced/ & 0.01 & \\
separated & & 0.82 \\
\hline Religion & & 0.07 \\
\hline Hindu & 0.81 & 0.10 \\
\hline Muslim & 0.08 & 0.01 \\
\hline Christian & 0.11 & 0.30 \\
\hline Other & 0.00 & 0.18 \\
\hline Schooling & & 0.22 \\
\hline Less than primary school & 0.35 & 0.61 \\
\hline Completed primary school & 0.25 & \\
\hline More than primary school & 0.40 & 0.11 \\
\hline Occupation & & \\
\hline Not working & 0.14 & \\
\hline Housework & 0.53 & \\
\hline Skilled work & 0.27 & \\
\hline Unskilled work & 0.05 & \\
\hline & & \\
\hline
\end{tabular}

The primary reason that individuals reported for not taking daily medications was that their BP had gone back to normal (63\% (95\% CI $48 \%$ to $76 \%$ ) among never initiated, $47 \%$ (95\% CI $33 \%$ to $61 \%$ ) among irregular treatment and $78 \%$ (95\% CI $71 \%$ to $84 \%$ ) among discontinued, figure 2). While substantially lower in magnitude, the next most common reasons were that the physician did not prescribe medications among those who never initiated treatment $(20 \%$ (95\% CI $10 \%$ to $34 \%)$ ), the nuisance of filling prescriptions among those took treatment irregularly (19\% (95\% CI 9\% to $33 \%)$ ) and a fear of side effects or addiction among those who discontinued treatment (12\% (95\% CI $8 \%$ to $18 \%)$ ).

\section{Hypertension knowledge}

Less than half $(45 \%$ (95\% CI $41 \%$ to $48 \%))$ of individuals reported heart problems as a consequence of uncontrolled BP and just 34\% (95\% CI 31\% to $37 \%$ ) reported stroke (figure 3). For knowledge of the effectiveness of BP medications and the importance of daily medication use, only $52 \%$ (95\% CI $49 \%$ to $55 \%$ ) listed BP medications as one of the three most effective ways of reducing BP, just 23\% (95\% CI 20\% to 26\%) listed BP medications as the most effective way to reduce BP, while $43 \%$ (95\% CI

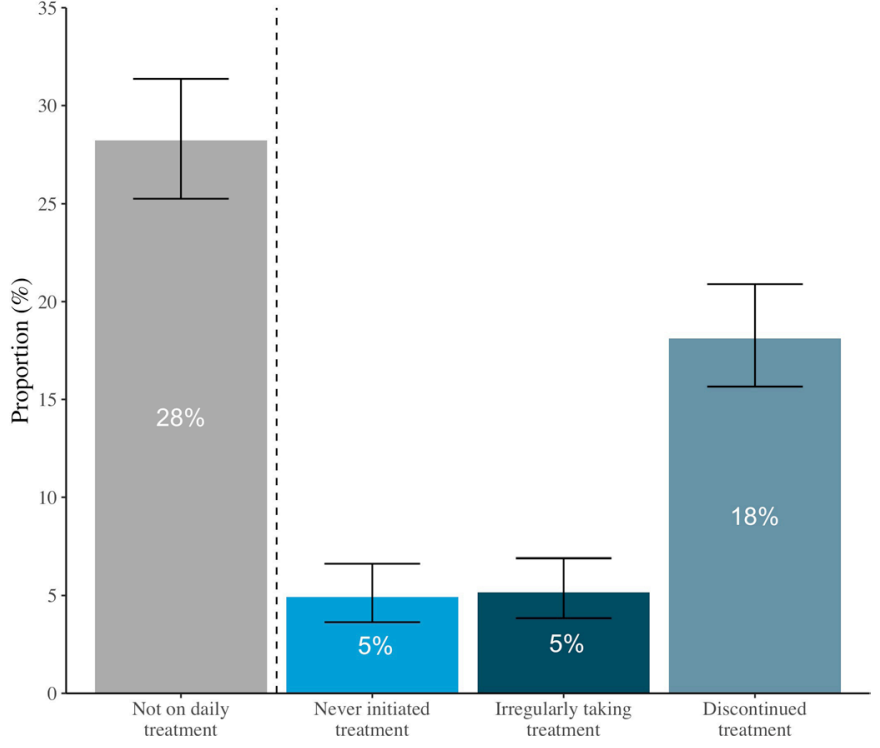

Figure 1 Proportion of non-daily treatment use overall and separated by type of non-use, 833 adults ages 30 and above with physician confirmed hypertension, Chennai, India, 2019. Among those that report non-daily treatment use, the proportion of those that never initiated medications is $18 \%$ (95\% Cl $13 \%$ to $23 \%$ ), the proportion that take medication but irregularly is $18 \%(95 \% \mathrm{Cl} 14 \%, 24 \%)$ and the proportion that discontinued treatment is $64 \%(95 \% \mathrm{Cl} 58 \%$ to $70 \%)$.

$40 \%$ to $47 \%$ ) of individuals believed that BP medications should be stopped from time to time.

\section{Associations between hypertension knowledge and daily medication use}

Knowledge regarding BP medications was strongly associated with daily medication use (figure 4). Individuals who reported that taking medication is the most effective way to reduce BP were $11 \%$ points ( $95 \%$ CI $4 \%$ to $19 \%$ ) more likely to take medications daily compared with individuals that reported other ways as most effective. Similarly, those that reported medication as one of the three most effective ways of reducing BP were $15 \%$ points $(95 \%$ CI $8 \%$ to $21 \%$ ) more likely to take medications daily compared with those that did not endorse BP medications as an effective way of reducing BP. Conversely, individuals that believed that BP medications should be stopped from time to time were $15 \%$ points ( $95 \%$ CI $-21 \%$ to $-9 \%$ ) less likely to take
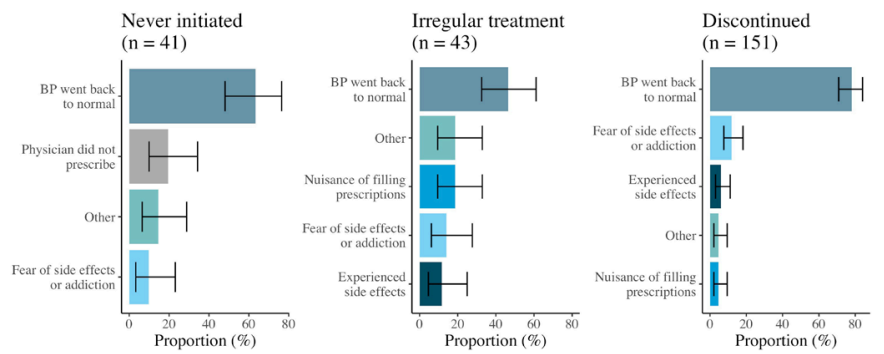

Figure 2 Self-reported reasons for not taking daily treatment by type of non-use, 235 adults ages 30 with physician confirmed hypertension who do not take daily medication, Chennai, India, 2019. BP, blood pressure. 


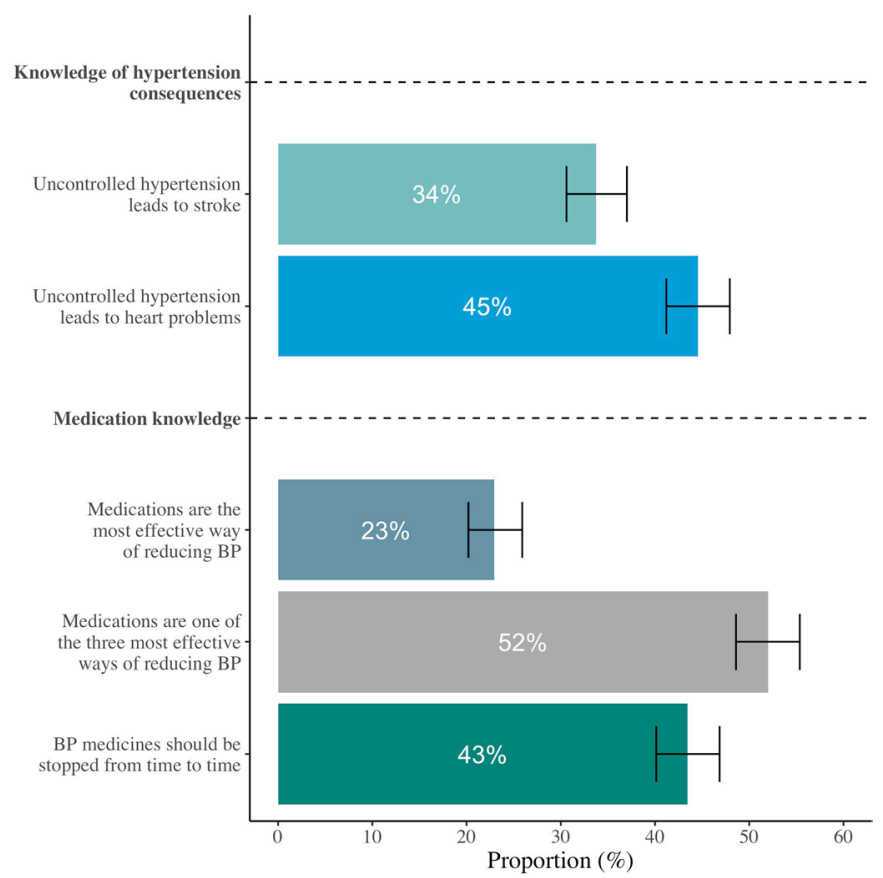

Figure 3 Knowledge of consequences of long-term uncontrolled hypertension, the most effective way to reduce blood pressure, and on regularity of blood pressure (BP) treatment, 833 adults ages 30 and above with physician confirmed hypertension, Chennai, India, 2019. Each bar represents the share of individuals that answered yes to the specific knowledge question.

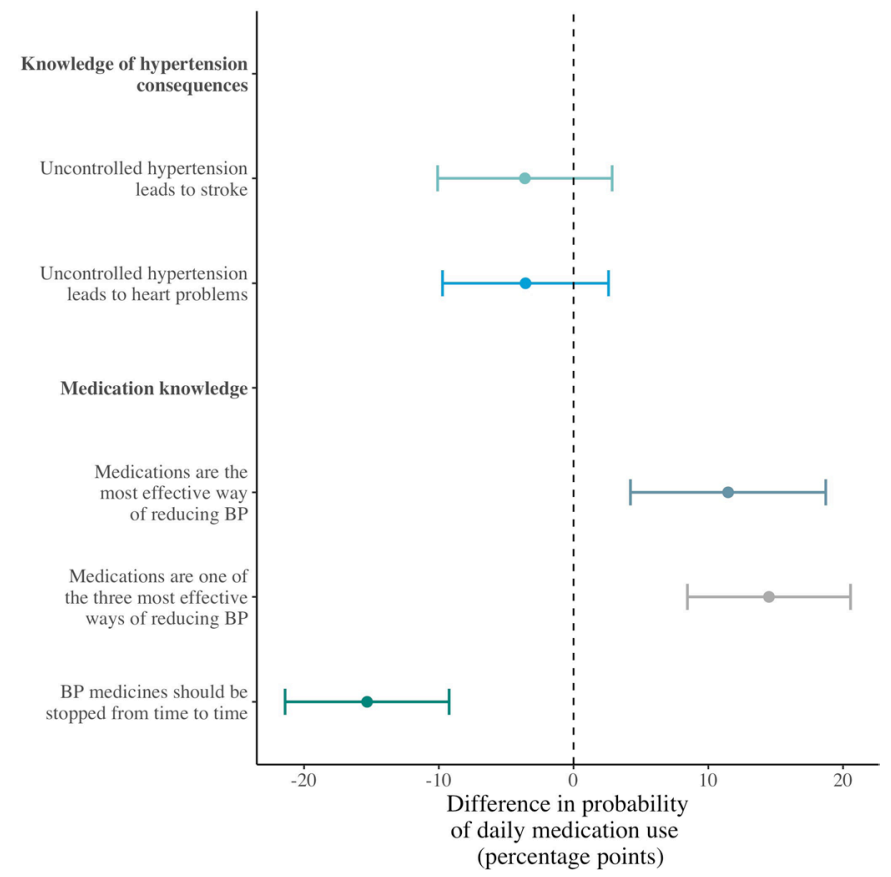

Figure 4 Association between blood pressure knowledge and daily medication use, 833 adults ages 30 and above with physician confirmed hypertension, Chennai, India, 2019. Estimates are presented as prevalence/probability differences with $95 \% \mathrm{Cls}$. The reference group for each estimate are those that did not answer yes to the specific knowledge statement. BP, blood pressure. medication daily. We found no evidence of an association between reporting that uncontrolled BP leads to stroke or heart problems and taking daily medications.

\section{DISCUSSION}

We found that almost one-third of adults in Chennai with physician-diagnosed hypertension were not taking daily antihypertensive medications. Treatment discontinuation, rather than non-initiation or irregular use, was by far the main source of non-daily treatment use. Incorrect knowledge towards treatment emerged as an important explanation for this pattern. The majority of individuals who discontinued medications said they did so because their BP had returned to normal and thus did not require further treatment. However, stopping treatment is not supported by the Indian care guidelines nor international hypertension care guidelines which indicate that once initiated, the vast majority of individuals with hypertension will need to remain on daily medication for substantial lengths of time or possibly their entire lives. ${ }^{25}{ }^{26} \mathrm{We}$ found further evidence that knowledge toward medication use may explain non-daily treatment, as nearly $40 \%$ of individuals believed that BP medications should be stopped from time to time. Importantly, individuals who reported this belief were also substantially less likely to take daily treatment. Future work is needed to determine whether improving individuals' knowledge that BP medications should be taken daily, even after BP levels reduce, can increase daily treatment use among individuals diagnosed with hypertension in urban India.

Less than half of individuals in our study reported heart problems as a main consequence of uncontrolled hypertension and less than one third linked hypertension to stroke. These findings are consistent with existing studies on hypertension knowledge in India. Busingye et al found that among 132 individuals who reported a hypertension diagnosis in rural South India, just 13 were aware that hypertension increases the risk of stroke and heart attacks. ${ }^{27}$ Similarly, Satish et al conducted qualitative interviews with hypertensive patients in the semiurban city of Dalkhola, West Bengal, and found that few respondents acknowledged a link between hypertension the risk of heart attacks or stroke. ${ }^{18}$ We hypothesised that individuals who were aware of the serious consequences of hypertension would find hypertension control more salient and thus be more likely to take daily treatment; however, we found no association between knowledge of hypertension consequences and daily treatment use. Since this was a descriptive finding, rather than a causal one, an important focus of future intervention work will be to determine if improving individuals' knowledge of hypertension consequences increases their probability of daily treatment.

More broadly, poor knowledge of hypertension consequences is especially important in this sample of individuals who had reported a physician diagnosis of hypertension and thus should have been counselled on 
the consequences of hypertension at the time of their diagnosis. While recent studies across India have documented poor primary care physician quality for several common ailments, ${ }^{28}{ }^{29}$ we are not aware of any studies that have evaluated physician counselling quality for hypertension in India. Determining how much of the hypertension knowledge gap can be attributed to poor quality of care and how much to patients' comprehension and memory of physician guidance is an important next step for designing interventions to increase hypertension knowledge.

While irregular treatment use is the primary explanation for non-daily treatment among individuals with hypertension in high-income countries, ${ }^{30}$ we find that deliberate treatment discontinuation is the more salient source of non-daily treatment among adults in Chennai. This finding, however, contrasts with two recent studies on treatment discontinuation in India that both report forgetfulness and a lack of money to purchase medication as the primary reasons for non-daily treatment use among individuals with diagnosed hypertension. ${ }^{31} 32$ Importantly, both these studies were among poorer populations and thus differences compared with our results may reflect the general socioeconomic conditions of the study individuals. Our finding, however, is consistent with the tuberculosis literature, another condition that is highly prevalent in India and requires that individuals take medications even after they no longer feel symptoms: a meta-analysis of qualitative studies investigating reasons for poor tuberculosis adherence finds that a major reason that individuals do not take their full treatment course is their belief that they have been cured after the initial doses. ${ }^{33}$ Collectively, these findings suggest that perceptions of medications and of illness as something to be cured rather than managed may be an important reason behind why BP is poorly managed in urban India and similar contexts. More research is needed to determine how to address these beliefs within the context of hypertension care and whether such changes result in improved BP outcomes.

Our study has some important limitations. Although we randomly selected wards within Chennai, we used a quota sampling approach and did not have a truly population-representative sample because we were not able to randomly sample individuals with physician diagnosed hypertension within wards. This was because random sampling within wards would have required first conducting a household census to determine which households had individuals with confirmed hypertension. This approach was infeasible within our current resources. As a result, our sample may not reflect the general population of adults with physician diagnosed hypertension. However, we selected respondents from across the entire city with broad representation of working and non-working adults, men and women, and older and younger adults to improve the external validity of the data. A related issue is that our sample under-represents higher socioeconomic status individuals since they were more challenging to survey since they often resided in gated or guarded housing structures. Unfortunately, this is a common limitation for household-based surveys across low- and middle-income countries (LMICs) ${ }^{34}$; given this limitation, our results are best interpreted as being relevant to the middle and lower socioeconomic strata of Chennai. Approximately one-third of contacted individuals did not participate in the survey. Given that we do not have information on these individuals, our results may further misrepresent the Chennai population if those that refused participation were systematically different from those that participated. Our measurement of current daily medication use was based on self-reports and thus may be subject to over-reporting and social desirability bias. This bias, however, would make our results conservative and suggest that even more individuals are not taking daily medications. Since we did not have information on what physicians told or prescribed individuals, we were not able to disentangle whether poor knowledge was due to poor physicians' involvement or because individuals did not recall or correctly follow what physicians advised. A related limitation is that we do not track individual's engagement in care. Lastly, we described differences in BP outcomes based on individuals' knowledge and beliefs and not the causal effect of these factors on BP. The results of our paper are thus best interpreted as hypothesis generating.

Despite these limitations, our study provides important contributions to the literature on hypertension in LMICs. We provide some of the first evidence on individuals' reported reasons for not taking daily medications and information on BP knowledge and beliefs in a major urban Indian city. Both these pieces of information are important for crafting and testing interventions that address the potential underlying reasons for treatment non-use among the large number of individuals with diagnosed hypertension in India and other LMICs.

Correction notice This article has been corrected since it first published. The provenance and peer review statement has been included.

Twitter Nikkil Sudharsanan @nikkilsud and Mohammed K Ali @mkali80

Acknowledgements We would like to thank Rigzom Wangchuk, A. Arulraj, and Christopher Glan for their research assistance and management of the data collection.

Contributors NS: conceptualisation, methodology, investigation, formal analysis, visualisation, writing — original draft, writing—review and editing; MKA: conceptualisation, methodology, investigation, writing — review and editing, supervision; MM: conceptualisation, methodology, investigation, writing—review and editing, supervision.

Funding This study received funding from the Foundations of Human Behavior Initiative at Harvard University (no award number). The funding organization had no role in any aspect of the study.

Disclaimer The funding organisation had no role in any aspect of the study. Competing interests None declared.

Patient and public involvement Patients and/or the public were not involved in the design, or conduct, or reporting, or dissemination plans of this research.

Patient consent for publication Not required.

Ethics approval This study received ethics approval from the Institutional Review Boards of Harvard University (IRB18-1546) in the USA and IFMR LEAD in India (IRB00007107). 
Provenance and peer review Not commissioned; externally peer reviewed.

Data availability statement Data are available on reasonable request. Data are available by emailing nikkil.sudharsanan@uni-heidelberg.de and will be made available online after publication.

Open access This is an open access article distributed in accordance with the Creative Commons Attribution Non Commercial (CC BY-NC 4.0) license, which permits others to distribute, remix, adapt, build upon this work non-commercially, and license their derivative works on different terms, provided the original work is properly cited, appropriate credit is given, any changes made indicated, and the use is non-commercial. See: http://creativecommons.org/licenses/by-nc/4.0/.

\section{ORCID iD}

Nikkil Sudharsanan http://orcid.org/0000-0003-1710-4634

\section{REFERENCES}

1 Stanaway JD, Afshin A, GBD 2017 Risk Factor Collaborators. Global, regional, and national comparative risk assessment of 84 behavioural, environmental and occupational, and metabolic risks or clusters of risks for 195 countries and territories, 1990-2017: a systematic analysis for the global burden of disease study 2017. Lancet 2018;392:1923-94.

2 Prabhakaran D, Anand S, Gaziano TA. Disease control priorities, (volume 5): cardiovascular, respiratory, and related disorders. World Bank Publications, 2017.

3 Kontis V, Cobb LK, Mathers CD. Three public health interventions could save 94 million lives in 25 years: global impact assessment analysis. Circulation 2019;140:715-25.

4 Ettehad D, Emdin CA, Kiran A, et al. Blood pressure lowering for prevention of cardiovascular disease and death: a systematic review and meta-analysis. Lancet 2016;387:957-67.

5 Sudharsanan N, Geldsetzer P. Impact of coming demographic changes on the number of adults in need of care for hypertension in Brazil, China, India, Indonesia, Mexico, and South Africa. Hypertension 2019;73:770-6.

6 Geldsetzer P, Manne-Goehler J, Theilmann M, et al. Diabetes and hypertension in India: a nationally representative study of 1.3 million adults. JAMA Intern Med 2018;178:363-72.

7 Prabhakaran D, Jeemon P, Ghosh S, et al. Prevalence and incidence of hypertension: results from a representative cohort of over 16,000 adults in three cities of South Asia. Indian Heart J 2017;69:434-41.

8 Gajalakshmi V, Lacey B, Kanimozhi V, et al. Body-mass index, blood pressure, and cause-specific mortality in India: a prospective cohort study of 500810 adults. Lancet Glob Health 2018;6:e787-94.

9 Sudharsanan N. Population-level mortality benefits of improved blood pressure control in Indonesia: a modelling study. Int $J$ Epidemiol 2018.

10 Central Drugs Standard Control Organization. Report of the corecommittee for revision of national list of essential medicines (online. Directorate General of Health Services, Ministry of Health \& Family Welfare, Government of India, 2015. https://cdsco.gov.in/opencms/ opencms/en/consumer/Essential-Medicines/

11 Prenissl J, Manne-Goehler J, Jaacks LM, et al. Hypertension screening, awareness, treatment, and control in India: a nationally representative cross-sectional study among individuals aged 15 to 49 years. PLoS Med 2019;16:e1002801.

12 Gabert R, Ng M, Sogarwal R, et al. Identifying gaps in the continuum of care for hypertension and diabetes in two Indian communities. BMC Health Serv Res 2017;17:846.
13 Ajzen I. The theory of planned behavior. Organ Behav Hum Decis Process 1991;50:179-211.

14 Bandura A. Human agency in social cognitive theory. Am Psychol 1989;44:1175-84.

15 Rosenstock IM. The health belief model and preventive health behavior. Health Educ Monogr 1974;2:354-86.

16 Kasprzyk D, Montaño DE, Fishbein M. Application of an integrated behavioral model to predict condom use: a prospective study among high HIV risk Groups1. J Appl Soc Psychol 1998;28:1557-83.

17 Kusuma YS. Perceptions on hypertension among migrants in Delhi, India: a qualitative study. BMC Public Health 2009;9:267.

18 Satish P, Khetan A, Barbhaya D, et al. A qualitative study of facilitators and barriers to cardiovascular risk factor control in a semiurban population in India. J Family Med Prim Care 2019;8:3773.

19 Office of the Registrar General \& Census Commissioner. SRS based abridged life tables 2014-18. New Delhi: India Ministry of Home Affairs, Government of India, 2019.

20 NITI Aayog, The World Bank, Ministry of Health \& Family Welfare. Healthy states progressive India: report on the ranks of states and Union territories, 2019.

21 District Census Handbook Chennai. Directorate of gensus operations, Tamil Nadu, 2011.

22 Office of the Registrar General \& Census Commissioner. Population by religious community - Tamil Nadu. Ministry of Home Affairs, Government of India, 2011.

23 Etikan I, Bala K. Sampling and sampling methods. Biom Biostat Int J 2017;5:00149.

24 Whelton PK, Carey RM, Aronow WS, et al. 2017 ACC/AHA/AAPA/ ABC/ACPM/AGS/APhA/ASH/ASPC/NMA/PCNA guideline for the prevention, detection, evaluation, and management of high blood pressure in adults. J Am Coll Cardiol 2018;71:e127-248.

25 Ministry of Health and Family Welfare. Screening, diagnosis, assessment, and management of primary hypertension in adults in India. government of India, 2016.

26 Unger T, Borghi C, Charchar F, et al. 2020 International Society of hypertension global hypertension practice guidelines. J Hypertens 2020;38:982-1004.

27 Busingye D, Arabshahi S, Evans RG, et al. Knowledge of risk factors for hypertension in a rural Indian population. Heart Asia 2019;11:e011136.

28 Das J, Holla A, Das V, et al. In urban and rural India, a standardized patient study showed low levels of provider training and huge quality gaps. Health Aff 2012;31:2774-84.

29 Kwan A, Daniels B, Saria V, et al. Variations in the quality of tuberculosis care in urban India: a cross-sectional, standardized patient study in two cities. PLoS Med 2018;15:e1002653.

30 Vrijens B, Antoniou S, Burnier M, et al. Current situation of medication adherence in hypertension. Front Pharmacol 2017;8:100.

31 Kakumani KV, Waingankar P. Assessment of compliance to treatment of diabetes and hypertension amongst previously diagnosed patients from rural community of Raigad district of Maharashtra. $J$ Assoc Physicians India 2016;64:36-40.

32 Kotian SP, Waingankar P, Mahadik VJ. Assessment of compliance to treatment of hypertension and diabetes among previously diagnosed patients in urban slums of Belapur, Navi Mumbai, India. Indian J Public Health 2019;63:348.

33 Munro SA, Lewin SA, Smith HJ, et al. Patient adherence to tuberculosis treatment: a systematic review of qualitative research. PLoS Med 2007;4:e238.

34 Woolard I, Leibbrandt M, de Villiers L. The South African national income dynamics study: design and methodological issues. 19, 2010. 